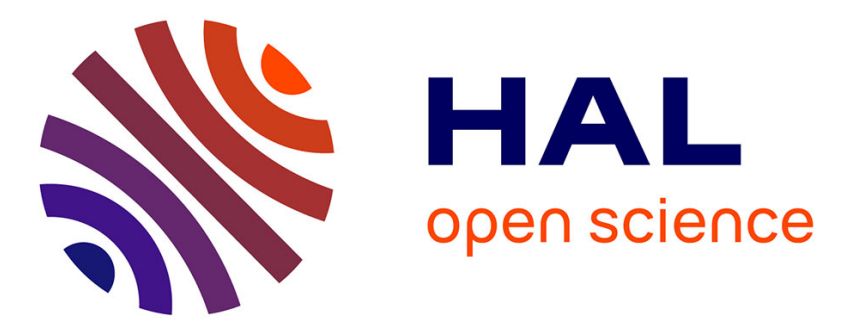

\title{
Dihydroxynonene mercapturic acid, a urinary metabolite of 4-hydroxynonenal, as a biomarker of lipid peroxidation.
}

Géraldine Peiro, Jacques Alary, Jean Pierre J. P. Cravedi, Estelle Rathahao, Jean-Paul Steghens, Françoise Guéraud

\section{To cite this version:}

Géraldine Peiro, Jacques Alary, Jean Pierre J. P. Cravedi, Estelle Rathahao, Jean-Paul Steghens, et al.. Dihydroxynonene mercapturic acid, a urinary metabolite of 4-hydroxynonenal, as a biomarker of lipid peroxidation.. BioFactors, 2005, 24 (1-4), pp.89-96. 10.1002/biof.5520240110 . hal-02674036

\section{HAL Id: hal-02674036 \\ https://hal.inrae.fr/hal-02674036}

Submitted on 31 May 2020

HAL is a multi-disciplinary open access archive for the deposit and dissemination of scientific research documents, whether they are published or not. The documents may come from teaching and research institutions in France or abroad, or from public or private research centers.
L'archive ouverte pluridisciplinaire HAL, est destinée au dépôt et à la diffusion de documents scientifiques de niveau recherche, publiés ou non, émanant des établissements d'enseignement et de recherche français ou étrangers, des laboratoires publics ou privés. 


\title{
Dihydroxynonene mercapturic acid, a urinary metabolite of 4-hydroxynonenal, as a biomarker of lipid peroxidation
}

\author{
Géraldine Peiro $^{\mathrm{a}}$, Jacques Alary ${ }^{\mathrm{a}}$, Jean-Pierre Cravedi ${ }^{\mathrm{a}}$, Estelle Rathahao ${ }^{\mathrm{a}}$, \\ Jean-Paul Steghens ${ }^{\mathrm{b}}$ and Françoise Guéraud ${ }^{\mathrm{a}, *}$ \\ a UMR 1089-Xénobiotiques, INRA/ENVT, BP 3, 31931, Toulouse Cedex 9, France \\ ${ }^{\mathrm{b}}$ Fédération de Biochimie, Hôpital Édouard Herriot, 69437, EA 3090, UCBLI, Lyon, France
}

\begin{abstract}
The objective of our study was to compare the information obtained through the use of three different urinary biomarkers of lipoperoxidation during the time course of a bromotrichloromethane $\left(\mathrm{BrCCl}_{3}\right)$ induced oxidative stress in rats. These biomarkers were malondialdehyde (MDA) measured by LC/MS after derivatization, the isoprostane 8 -iso-PGF $2 \alpha$ measured by enzyme immunoassay and 1,4-dihydroxynonene mercapturic acid (DHN-MA), the major 4-hydroxynonenal urinary metabolite [1], measured by LC-MS. Male Wistar rats received a single dose of $100 \mu \mathrm{L} / \mathrm{kg} \mathrm{BrCCl}$ per os and lipid peroxidation was estimated every day for a 4-day-period after treatment. MDA, 8-iso-PGF Pa $_{\alpha}$ and DHN-MA significantly increased in response to $\mathrm{BrCCl}_{3}$ treatment for this period of time, and DHN-MA showed the main increase during the $24-48 \mathrm{~h}$ period after treatment.
\end{abstract}

Keywords: Lipid peroxidation, oxidative stress, 4-hydroxynonenal, biomarker, dihydroxynonene mercapturic acid, urine

Abbreviations: $\mathrm{BHT}$, butylated hydroxytoluene; $\mathrm{BrCCl}_{3}$, bromotrichloromethane; $\mathrm{CRM}$, consecutive reaction monitoring; 2,3-DAN, 2,3-diaminophtalene; DHN, 1,4-dihydroxynonene; EIA, enzyme immunoassay; HNA, 4-hydroxynonenoic acid; 4-HNE, 4-hydroxynonenal; 8-iso-AchE, 8-iso-PGF $\mathrm{P}_{2 \alpha}$ acetylcholinesterase conjugate; 8-iso-PGF $2 \alpha$, 8-iso-prostaglandin $\mathrm{F}_{2 \alpha}$; MA, mercapturic acid; MDA, malondialdehyde; PBI, phenyl-benzimidazole; PUFA, polyunsaturated fatty acid; TIC, total ion current; SIM, single ion monitoring

\section{Introduction}

Lipid peroxidation is one of the major processes that occur as a result of oxidative stress induced by radicals. Polyunsaturated fatty acids (PUFAs), which are constituents of membrane phospholipids or lipoproteins, are highly susceptible to reaction with free radicals. This reaction leads to the formation of conjugated dienes, lipid hydroperoxides and end-products such as alkanes, aldehydes and isoprostanes [16] that are more stable than free radicals.

Numerous compounds have been proposed as lipid peroxidation biomarkers. However, only a limited number can be used in vivo for non invasive explorations. The most widely used index of lipid peroxidation in vitro and in vivo is the measurement of malondialdehyde (MDA), with the TBARS

\footnotetext{
*Address for correspondence: F. Guéraud, UMR 1089-Xénobiotiques, INRA/ENVT, BP 3, 31931, Toulouse Cedex 9, France. Tel.: +33561285 383; Fax: +33561285244; E-mail: fgueraud@toulouse.inra.fr.
} 


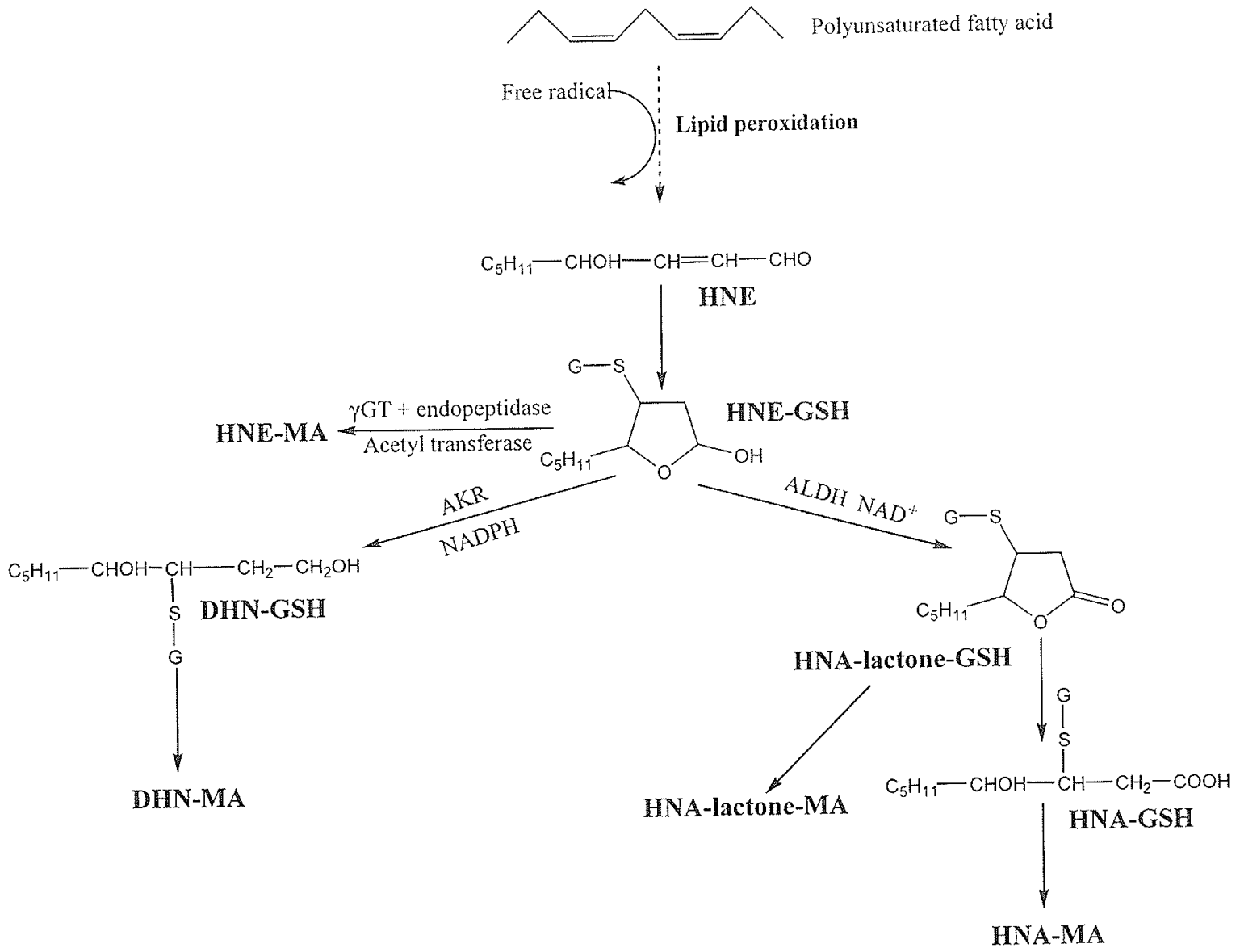

Fig. 1. Formation of 4-HNE urinary metabolites in the rat.

assay [10]. This method has several drawbacks [8] but new methods have been recently developed to measure specifically MDA, using HPLC-UV detection [22].

Recently, a new group of prostaglandin (PGF)-like compounds known as $\mathrm{F}_{2}$-isoprostanes, produced in vivo by a non-cyclooxygenase free radical-catalyzed mechanism involving peroxidation of arachidonic acid, was discovered by Morrow et al. [18]. These PGF-like compounds are detectable in human biological fluids and their formation increases markedly in animal models under increased oxidative stress status [18]. The main $\mathrm{F}_{2}$-isoprostane produced in vivo is 8-iso-prostaglandin $\mathrm{F}_{2 \alpha}$ (8-iso- $\mathrm{PGF}_{2 \alpha}$ ) [20]. Its measurement provides a valuable and accurate approach to assess oxidative stress in vivo [21].

The aldehydic compound 4-hydroxynonenal (4-HNE) is one important end-product of the lipid peroxidation of $\omega-6$ PUFAs [10]. 4-HNE is considered as a reliable index of both the extent and consequences of lipid peroxidation in tissues [9]. But, owing to its high reactivity, 4-HNE readily reacts with several endogenous compounds $[11,24]$. Unfortunately, this reactivity is a serious drawback for its use as a valuable lipid peroxidation biomarker. But this drawback could be circumvented by the use of an urinary end-product of 4-HNE metabolism in vivo.

When exogenously administered, 4-HNE gave DHN-MA as the main urinary metabolite (Fig. 1) in the rat [1]. DHN-MA has been also identified as a physiological constituent of rat and human urine [2].

The purpose of the present study was to investigate those three urinary biomarkers of oxidative stress 
in the rat after bromotrichloromethane $\left(\mathrm{BrCCl}_{3}\right)$ oral administration, which induces free radical damage in liver, and to determine whether DHN-MA is a convenient biomarker of lipid peroxidation in this animal model in comparison to MDA or 8 -iso- $\mathrm{PGF}_{2 \alpha}$. To obtain those three parallel quantifications, we used enzyme immunoassay (EIA) to assess 8 -iso-PGF $2 \alpha$, LC-MS for the determination of DHN-MA as describe before with slight modifications [2], and a new LC-MS quantification method for the specific MDA assay in urine.

\section{Materials and methods}

\subsection{Chemicals}

$\mathrm{N}$-acetyl-cysteine, $\mathrm{BrCCl}_{3}$, butylated hydroxytoluene (BHT), MDA, sodium borodeuteride and deuterated acetic anhydride were from Sigma-Aldrich (Saint-Quentin-Fallavier, France). 2,3-Diaminonaphtalene (2,3-DAN) was from ICN Biomedicals (Orsay, France), and deuterated cysteine from EurisoTop (Saint-Aubin, France). 8-iso-PGF $2 \alpha$ was from SpiBio (Massy, France). The 8-iso-PGF $2 \alpha^{-}$ acetylcholinesterase conjugate and the 8 -iso- $\mathrm{PGF}_{2 \alpha}$-specific antiserum were a generous gift from $\mathrm{Dr}$ C. Créminon (CEA-Saclay, Gif-sur-Yvette, France). $\left[{ }^{3} \mathrm{H}\right] 1,4-D H N-M A$ was synthesized from racemic tritiated 4-HNE as previously described [2] with a specific activity of $180 \mathrm{GBq} / \mathrm{mmol}$. HNE-diethylacetal was synthesized as described by Esterbauer et al. [12] and 4-HNE was released by hydrolysis with $1 \mathrm{mM}$ $\mathrm{HCl}$.

\subsection{Synthesis of deuterated DHN-MA}

$\left[{ }^{2} \mathrm{H}\right] \mathrm{N}$-acetyl-cysteine was synthesized from $\left[{ }^{2} \mathrm{H}\right]$ acetic-anhydride and $\left[{ }^{2} \mathrm{H}\right]$ cysteine. $\left[{ }^{2} \mathrm{H}\right] \mathrm{DHN}-\mathrm{MA}$ was synthesized as previously described for DHN-MA [1,2] using sodium borodeuteride for the reduction step.

\subsection{Animals}

Ten male Wistar rats (230-250 g) (Harlan, Granat, France) were fed a semi purified diet (AIN 76, from UAR, Epinay, France).

The animals were given by gavage a single dose of $\mathrm{BrCCl}_{3}(0.1 \mathrm{~mL} / \mathrm{kg})$ dissolved in paraffin oil (1/9, $\mathrm{v} / \mathrm{v})$. Control rats received an equal volume of paraffin oil. Urine was collected daily in plastic tubes kept in ice, containing $1 \mathrm{ml}$ of BHT $(360 \mathrm{mM})$ dissolved in ethanol. Urine was stored at $-80^{\circ} \mathrm{C}$ until analyses.

Experiments were performed according to institutional guidelines governing animal experimentation.

\subsection{LC-MS quantification of DHN-MA}

Solid phase extraction and HPLC purification of DHN-MA from urine were performed as previously described [2] using $\left[{ }^{3} \mathrm{H}\right] \mathrm{DHN}-\mathrm{MA}$ as tracer.

$\left.{ }^{2} \mathrm{H}\right] \mathrm{DHN}-\mathrm{MA}$ was used as internal standard for MS quantitation of DHN-MA. Each dry urine extract was dissolved in $50 \mu \mathrm{L}$ of mobile phase containing $1 \mathrm{ng} / \mu \mathrm{L}$ internal standard. The LC/MS analyses were carried out by injecting $20 \mu \mathrm{L}$ of the final solution.

LC was used to introduce the analysis solution into the ion source at a $0.2 \mathrm{~mL} / \mathrm{min}$ flow rate using a Thermo Separation P400 pump (Thermo Electron, Les Ulis, France) fitted with a Rheodyne injector. 
The LC column was a Kromasil $100 \mathrm{C} 18(250 \times 2 \mathrm{~mm}, 5 \mu \mathrm{m})$ column and the mobile phase was: water/acetonitrile/formic acid $(90: 10: 1, \mathrm{v} / \mathrm{v} / \mathrm{v})$.

DHN-MA detection was carried out using a quadrupole ion trap mass spectrometer (Finnigan LCQ, Thermo Finnigan, Les Ulis, France) equipped with an electrospray ionization source operating in the positive ion mode. $\mathrm{MS}^{3}$ experiments were performed and the signals of the $\mathrm{m} / \mathrm{z} 164$ and $\mathrm{m} / \mathrm{z} 169$ fragment ions detected respectively for the target and deuterated compounds, were extracted for integration and quantification.

The calibration curve was obtained by LC-MS ${ }^{3}$ analyses of calibration solutions prepared from $0.25 \mathrm{ng} / \mu \mathrm{l}$ to $5 \mathrm{ng} / \mu \mathrm{l}$. The linearity of the analytical method and reproducibility of injections were evaluated by several injections of calibration solutions. Three injections of each standard solution in a 48 h-period led to a linear standard graph with a relative standard deviation lower than $15 \%$ and a determination coefficient $\left(\mathrm{R}^{2}\right)$ of 0.998 .

To evaluate the reproducibility of the quantification method, the urine of 12 rats was collected, pooled and separated in 6 fractions. The mean DHN-MA amount excreted in $24 \mathrm{~h}$ measured from those fractions had a relative standard deviation of $6.4 \%$.

\subsection{LC/MS quantification of MDA}

Urinary MDA was measured after a derivatization procedure using diaminonaphtalene as previously described for HPLC-UV quantitation [22], except that the detection was carried out with a single quadrupole mass spectrometer in the positive electrospray ionisation mode. This enables the introduction of phenyl-benzimidazole (PBI) as an internal standard. This compound, which has the same molecular weight as MDA derivative, exhibited a very similar chromatographic and ionisation behaviour as the diazepinium of MDA.

Measurements were made with a P4000 liquid chromatograph connected to an autosampler AS 3000 and a single quadrupole mass Navigator Aqua detector (Thermo Finnigan) with a silica based $\mathrm{C} 18$ UP3BioP2 column $(150 \times 2 \mathrm{~mm}, 5 \mu \mathrm{m})$ (Interchim, Montluçon, France) held at $50^{\circ} \mathrm{C}$. The injected sample volume was $5 \mu \mathrm{L}$ and the flow rate was $230 \mu \mathrm{L} / \mathrm{min}$. Analyses were performed following the mobile phase: $85 \%$ of ammonium acetate (final concentration: $5 \mathrm{mM}, \mathrm{pH} 1.8$ ), and $15 \%$ of methanol/acetonitrile $(50 / 50, \mathrm{v} / \mathrm{v})$.

The chromatograms were recorded as a total ion current (TIC) and in a single ion monitoring (SIM) mode at $\mathrm{m} / \mathrm{z}\left(\mathrm{M}+\mathrm{H}^{+}\right)$equaled to 183.2 and 195.2 for the diazepinium of acetaldehyde, MDA and PBI, respectively.

\subsection{EIA quantification of 8 -iso- $P G F_{2 \alpha}$}

The assay is based on competitive EIA $[19,25]$ with 8-iso-PGF $2 \alpha$-linked acetylcholinesterase enzyme as tracer. Detection was recorded at $414 \mathrm{~nm}$ using a plate reader (Thermo Labsystems, Cergy-Pontoise, France).

\subsection{Statistics}

Data are presented as means \pm SD and statistical analyses were determined by a one-way ANOVA followed by a Dunnett's test for comparison of means. 


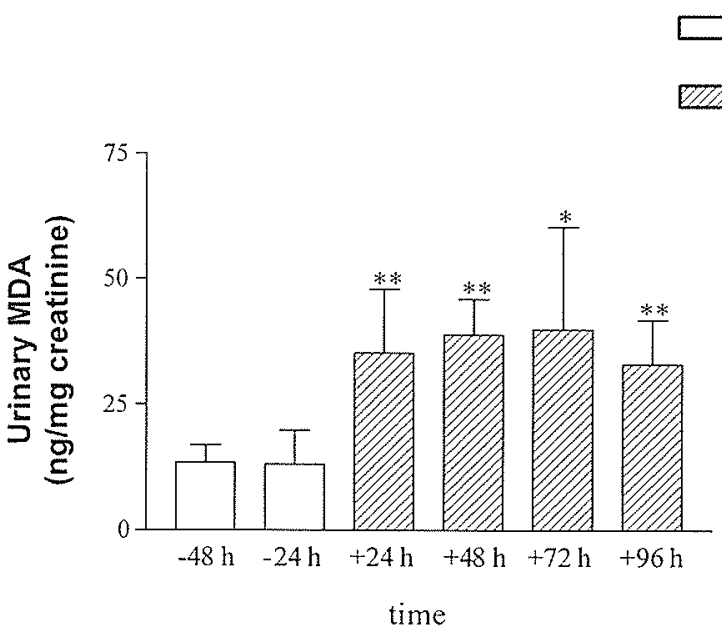

Fig. 2. Urinary excretion of $\mathrm{MDA}$ before and after $\mathrm{BrCCl}_{3}$ administration to rats. Values are mean $\pm \mathrm{SD}$ from five animals. $*=$ significantly different from pre-treatment period $(p<0.05)$. $* *=$ very significantly different from pre-treatment period $(p<0.01)$.

\section{Results and discussion}

In the current study, we compared the urinary excretion of DHN-MA obtained in response to lipid peroxidation induction to the one of two other biomarkers of lipid peroxidation, namely MDA, which has been widely used for decades, and free 8 -iso-PGF $2 \alpha$, which was recently considered to be the best lipid peroxidation biomarker currently available [14].

All tested urinary biomarkers of lipid peroxidation were increased after the administration of $\mathrm{BrCCl}_{3}$. In all cases, the maximum excretion was observed in the $24-48 \mathrm{~h}$ urine fraction after the treatment and the excretion tended to return to background level after four days. In control rats, the excretion of the three compounds did not increase after gavage with paraffin oil.

We observed 2.9 times more MDA in the $24-48 \mathrm{~h}$ post-treatment period urine $(38.9 \pm 7.1 \mathrm{ng} / \mathrm{mg}$ creatinine) compared to the pre-treatment period urine (13.4 $\pm 3.5 \mathrm{ng} / \mathrm{mg}$ creatinine) $(p<0.01)$ (Fig. 2$)$.

We also observed 3.2 times more 8-iso $\mathrm{PGF}_{2 \alpha}$ in the $24-48 \mathrm{~h}$ post-treatment period urine $(4.2 \pm$ $1.7 \mathrm{ng} / \mathrm{mg}$ creatinine) compared to the pre-treatment period urine $(1.3 \pm 0.3 \mathrm{ng} / \mathrm{mg}$ creatinine $)(p<$ 0.01) (Fig. 3).

DHN-MA concentration increased 5.3 times after treatment, from $5.5 \pm 1.3 \mathrm{ng} / \mathrm{mg}$ creatinine in the pre-treatment period urine to $29.4 \pm 10.2 \mathrm{ng} / \mathrm{mg}$ creatinine in the $24-48 \mathrm{~h}$ post-treatment period urine $(p<0.01)$ (Fig. 4).

To assess the relevance of DHN-MA as a possible biomarker of lipid peroxidation in vivo, as compared with $\mathrm{MDA}$ and 8 -iso- $\mathrm{PGF}_{2 \alpha}$, several criteria that should be met by an ideal biomarker were considered, namely specificity, sensitivity, stability and convenience [6,14].

Lipid peroxidation biomarkers are produced during the peroxidative process of PUFAs contained in the phospholipids of biomembranes or in lipoproteins. A marker of lipid peroxidation in the whole body must reflect the specific degradation of these PUFAs. It is important to keep in mind that the composition of PUFAs is very dependent on the species, the tissue and the composition of the diet.

MDA results from the oxidative degradation of PUFAs with more than two methylene interrupted double bounds [11]. The precursors for MDA are mainly arachidonic, eicosapentaenoic, docosapentaenoic 

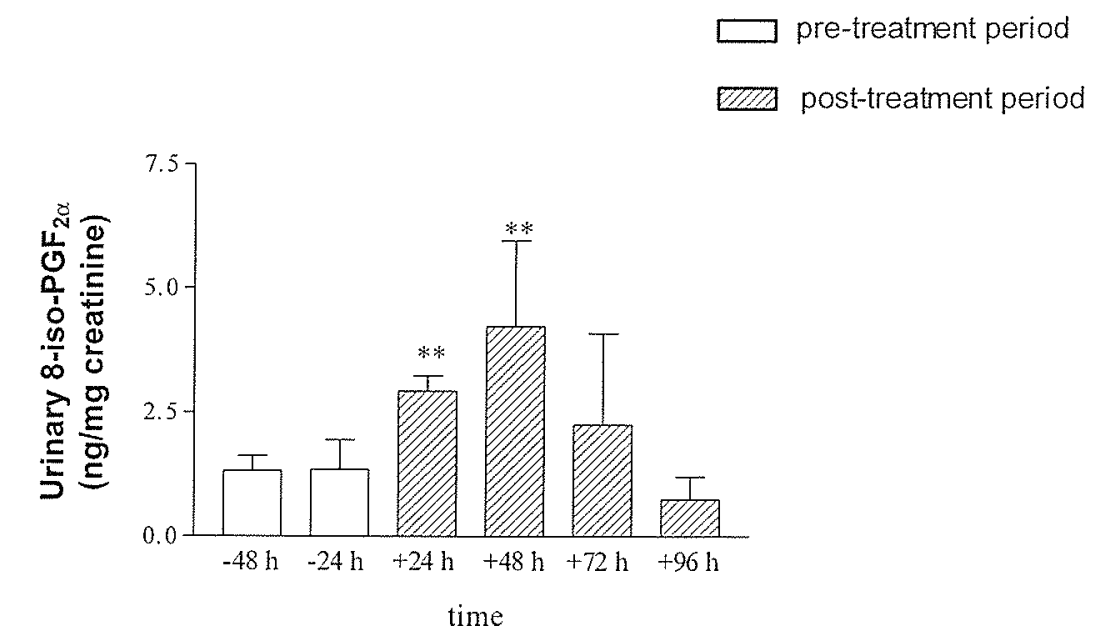

Fig. 3. Urinary excretion of 8-iso- $\mathrm{PGF}_{2 \alpha}$ before and after $\mathrm{BrCCl}_{3}$ administration to rats. Values are mean $\pm \mathrm{SD}$ from five animals. $* *=$ very significantly different from pre-treatment period $(p<0.01)$.

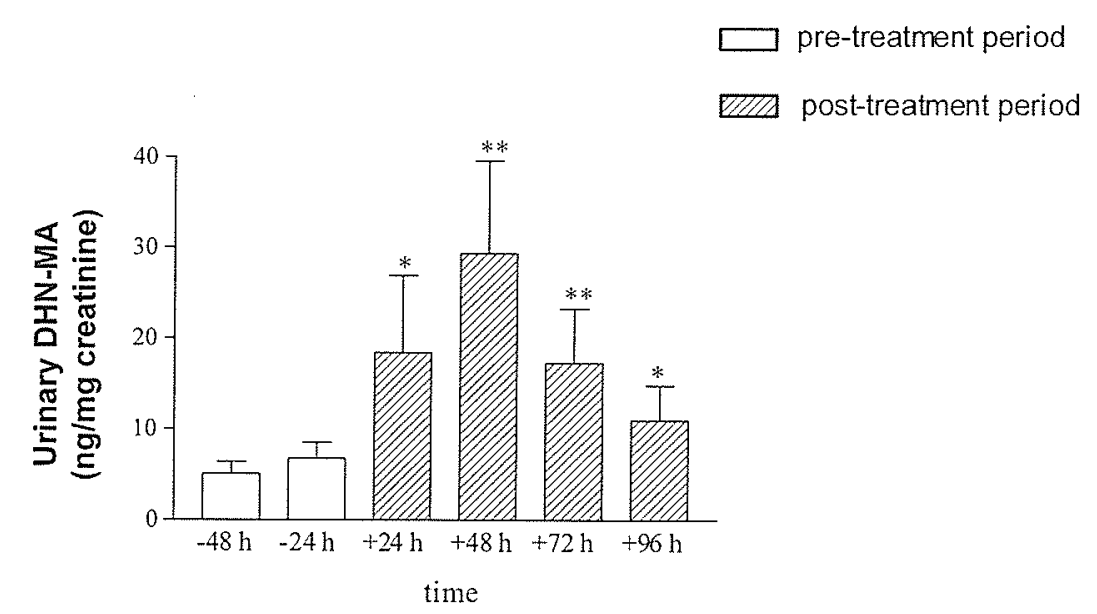

Fig. 4. Urinary excretion of $\mathrm{DHN}-\mathrm{MA}$ before and after $\mathrm{BrCCl}_{3}$ administration to rats. Values are mean $\pm \mathrm{SD}$ from five animals. $*=$ significantly different from pre-treatment period $(p<0.05)$. ** = very significantly different from pre-treatment period $(p<0.01)$.

and docosahexaenoic acids [11]. In rat liver biomembranes, among these PUFAs, only arachidonic is a major PUFA [5].

$\mathrm{F}_{2}$-isoprostanes are formed only from arachidonic acid [17]. So, the measurement of urinary 8-iso$\mathrm{PGF}_{2 \alpha}$ only represents the degradation of arachidonic acid.

DHN-MA is the major urinary metabolite of 4-HNE [1] which comes from the peroxidation of PUFAs from the $\omega-6$ family, mainly linoleic and arachidonic acids that represent a large proportion of fatty acids in rat liver biomembranes [5].

The measurement of 8-iso- $\mathrm{PGF}_{2 \alpha}$ does not depend on the presence of lipid peroxides in the diet [13]. On the contrary, the influence of the diet is especially relevant for MDA whose urinary excretion was found to be partly due to the presence of oxidized PUFAs in food [7]. The presence of 4-HNE in foodstuffs has been reported [15]. Although no data exists concerning bioavailability of 4-HNE after 
oral administration, it is expected that this rather lipophilic compound is well absorbed through the digestive tract. In that case, it cannot be ruled out that the presence of DHN-MA in urine is partly due to the ingestion of exogenous 4-HNE.

In terms of sensitivity, the DHN-MA increase amounted to about 5 times the control value after 48 hours whereas the MDA and 8-iso-PGF $\mathrm{PG}_{2 \alpha}$ showed a 3 fold increase after $\mathrm{BrCCl}_{3}$ administration. 4-HNE is another specific indicator of peroxidation which formation is very specific of free radical lipid peroxidation [4]. 4-HNE is detected as a physiological component in human plasma [23] and in other tissues, but its amount increases during oxidative stress [26]. The use of 4-HNE measurement as an index of lipid peroxidation is rather controversial because free 4-HNE is chemically reactive and reacts with endogenous compounds such as amino acids and proteins [24]. Measurement of DHN-MA allows measurement of the peroxidation index originating from 4-HNE without the drawbacks due to the reactivity of this compound.

In terms of stability, no formation of DHN-MA can occur during storage since (i) 4-HNE, its precursor, is not present in urine [1] and (ii) the synthesis of DHN-MA cannot occur without enzyme action [3]. Moreover, DHN-MA can not be degraded since it does not bear any chemical reactive group. When urine samples were added with $\left[{ }^{3} \mathrm{H}\right] \mathrm{DHN}-\mathrm{MA}$ and stored at $-20^{\circ} \mathrm{C}$ for six months, no decomposition of DHN-MA occurred (data not shown). In comparison, $\mathrm{MDA}$ and 8-iso-PGF $2 \alpha$ are moderately stable in urine at $-20^{\circ} \mathrm{C}$ and their storage for a few months requires the addition of BHT.

The measurement of lipid peroxidation biomarkers in urine is convenient because this matrix is available by non-invasive sampling techniques and measurements in urine over quite a long period of time (up to $24 \mathrm{~h}$ ) can provide an integrated index of oxidative stress, which can be useful for chronic injuries. The detection of MDA, 8-iso-PGF $2 \alpha$ and 4-HNE is possible in plasma, and would give a more instantaneous view of the oxidative status, but the problem of stability and artefactual production of these compounds in the plasma is much greater than in urine due to the presence of lipids and proteins.

In our study, we measured MDA by LC-MS, which is a more specific method than the TBARS assay. However, this technique does not solve the problem of the specificity of MDA used as an indicator of endogenous lipid peroxidation. In addition, this sophisticated technique necessitates the use of expensive apparatus and experienced analysts. This problem is even more important for DHN-MA analysis which requires a long and expensive analytical procedure. The currently used method is suitable for research purposes, but not for routine analysis. To overcome these problems, an enzyme immunoassay method is currently being developed in our laboratory for the determination of urinary DHN-MA in a fast and very specific way.

\section{Acknowledgements}

Thanks are due to R. Gazel and F. Blas y Estrada (INRA, Toulouse, France) for their care during animal experiments. We also appreciate the kindness of Dr C. Créminon (CEA-Saclay, Gif-sur-Yvette, France) in providing the 8-isoprostane-specific antiserum.

\section{References}

[1] J. Alary, F. Bravais, J.P. Cravedi, L. Debrauwer, D. Rao and G. Bories, Mercapturic acid conjugates as urinary end metabolites of the lipid peroxidation product 4-hydroxy-2-nonenal in the rat, Chem. Res. Toxicol. 8 (1995), 34-39.

[2] J. Alary, L. Debrauwer, Y. Fernandez, J.P. Cravedi, D. Rao and G. Bories, 1,4-Dihydroxynonene mercapturic acid, the major end metabolite of exogenous 4-hydroxy-2-nonenal, is a physiological component of rat and human urine, Chem. Res. Toxicol. 11 (1998), 130-135. 
[3] J. Alary, Y. Fernandez, L. Debrauwer, E. Perdu and F. Gueraud, Identification of intermediate pathways of 4 hydroxynonenal metabolism in the rat, Chem. Res. Toxicol. 16 (2003), 320-327.

[4] A. Benedetti, M. Comporti and H. Esterbauer, Identification of 4-hydroxynonenal as a cytotoxic product originating from the peroxidation of liver microsomal lipids, Biochim. Biophys. Acta 620 (1980), 281-296.

[5] R. Christon, Y. Fernandez, C. Cambon-Gros, A. Periquet, P. Deltour, C.L. Léger and S. Mitjavila, The effect of dietary essential fatty acid deficiency on the composition and properties of the liver microsomal membrane of rats, J. Nutr. 118 (1988), 1311-1318

[6] L.L. de Zwart, J.H. Meerman, J.N. Commandeur and N.P. Vermeulen, Biomarkers of free radical damage applications in experimental animals and in humans, Free Radic. Biol. Med. 26 (1999), 202-226.

[7] H.H. Draper, A.S. Csallany and M. Hadley, Urinary aldehydes as indicators of lipid peroxidation in vivo, Free Radic Biol. Med. 29 (2000), 1071-1077.

[8] H.H. Draper and M. Hadley, Malondialdehyde determination as index of lipid peroxidation, Methods Enzymol. 186 (1990), 421-431.

[9] H. Esterbauer, Estimation of peroxidative damage. A critical review, Pathol. Biol. (Paris) 44 (1996), 25-28.

[10] H. Esterbauer and K.H. Cheeseman, Determination of aldehydic lipid peroxidation products: Malonaldehyde and 4. hydroxynonenal, Methods Enzymol. 186 (1990), 407-421.

[11] H. Esterbauer, R.J. Schaur and H. Zollner, Chemistry and biochemistry of 4-hydroxynonenal, malonaldehyde and related aldehydes, Free Radic. Biol. Med. 11 (1991), 81-128.

[12] H. Esterbauer and W. Weger, Uber die wirkungen von aldehyden auf gesunde und maligne zellen, 3: mitt: Synthese von homologen 4-hydroxy-2-alkenalen, II, Monatsch. Chem. 98 (1967), 1994-2000.

[13] N.K. Gopaul, B. Halliwell and E.E. Anggard, Measurement of plasma $F_{2}$-isoprostanes as an index of lipid peroxidation does not appear to be confounded by diet, Free Radic. Res. 33 (2000), 115-127.

[14] B. Halliwell, Lipid peroxidation, antioxidants and cardiovascular disease: How should we move forward? Cardiovasc. Res. 47 (2000), 410-418.

[15] J. Lang, C. Celotto and H. Esterbauer, Quantitative determination of the lipid peroxidation product 4-hydroxynonenal by high-performance liquid chromatography, Anal. Biochem. 150 (1985), 369-378.

[16] K. Moore and L. Jackson Roberts II, Measurement of lipid peroxidation, Free Radic. Res. 28 (1998), 659-671.

[17] J.D. Morrow, J.A. Awad, H.J. Boss, I.A. Blair and L.J. Roberts, 2nd, Non-cyclooxygenase-derived prostanoids ( $F_{2}-$ isoprostanes) are formed in situ on phospholipids, Proc. Natl. Acad. Sci. USA 89 (1992), 10721-10725.

[18] J.D. Morrow, K.E. Hill, R.F. Burk, T.M. Nammour, K.F. Badr and L.J. Roberts, 2nd, A series of prostaglandin F2-like compounds are produced in vivo in humans by a non-cyclooxygenase, free radical-catalyzed mechanism, Proc. Natl. Acad. Sci. USA 87 (1990), 9383-9387.

[19] P. Pradelles, J. Grassi and J. Maclouf, Enzyme immunoassays of eicosanoids using acetylcholine esterase as label: An alternative to radioimmunoassay, Anal. Chem. 57 (1985), 1170-1173.

[20] L.J. Roberts, 2nd, K.P. Moore, W.E. Zackert, J.A. Oates and J.D. Morrow, Identification of the major urinary metabolite of the $\mathrm{F}_{2}$-isoprostane 8-iso-prostaglandin F2alpha in humans, J. Biol. Chem. 271 (1996), 20617-20620.

[21] L.J. Roberts and J.D. Morrow, Measurement of $\mathrm{F}(2)$-isoprostanes as an index of oxidative stress in vivo, Free Radic. Biol. Med. 28 (2000), 505-513.

[22] J.P. Steghens, A.L. van Kappel, I. Denis and C. Collombel, Diaminonaphtalene, a new highly specific reagent for HPLC-UV measurement of total and free malondialdehyde in human plasma or serum, Free Radic. Biol. Med. 31 (2001), $242-249$.

[23] H. Strohmaier, H. Hinghofer-Szalkay and R.J. Schaur, Detection of 4-hydroxynonenal (HNE) as a physiological component in human plasma, J. Lipid Mediat. Cell Signal. 11 (1995), 51-61.

[24] K. Uchida and E.R. Stadtman, Modification of histidine residues in proteins by reaction with 4-hydroxynonenal, Proc. Natl. Acad. Sci. USA 89 (1992), 4544-4548.

[25] Z. Wang, G. Ciabattoni, C. Creminon, J. Lawson, G.A. Fitzgerald, C. Patrono and J. Maclouf, Immunological characterization of urinary 8-epi-prostaglandin F2 alpha excretion in man, J. Pharmacol. Exp. Ther. 275 (1995), 94-100.

[26] N. Zarkovic, 4-hydroxynonenal as a bioactive marker of pathophysiological processes, Mol. Aspects Med. 24 (2003) 281-291. 